Revista Tecné, Episteme y Didaxis: TED. Año 2014, Número Extraordinario. ISSN Impreso: 0121-3814, ISSN web: 2323-0126

Memorias, Sexto Congreso Internacional sobre Formación de Profesores de Ciencias. 08 al 10 de octubre de 2014, Bogotá

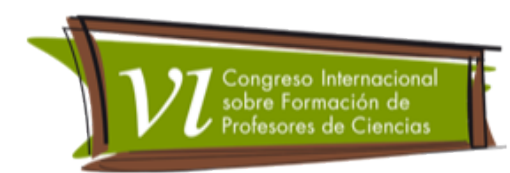

\title{
Rio Apodi-Mossoró: uma unidade didática CTSA para a formação inicial de professores de Química
}

Nunes Albino Oliveira', Dantas, Josivânia Marisa², Souza, Luiz Di³

Categoria 2. Trabalhos de investigação (Concluído)

\section{Resumo}

O presente trabalho descreve a elaboração e avaliação de uma unidade didática para trabalhar as relações CTSA junto a licenciandos em química no sertão nordestino. Aqui relatamos a elaboração da proposta e sua avaliação em uma oficina ofertada a estudantes da Universidade do Estado do Rio Grande do Norte. A unidade está subdividida em três partes: Aspectos Epistemológicos das Ciências Naturais; $O$ Movimento CTSA e o Ensino de Ciências e, por fim, apresentado um tema local para o ensino de química dentro de uma perspectiva CTSA: O Rio Apodi/Mossoró. Os resultados mostram que os estudantes que participaram da oficina avaliam positivamente a unidade, apresentando possibilidades de usar as atividades em suas salas de aula, e identificam como significativos os conteúdos trabalhados, afirmando que esses aspectos estavam ausentes em sua formação.

\section{Palavras chaves}

Unidade Didática, Formação Inicial, Química, CTSA

\section{Objetivo}

Avaliar uma unidade didática para a inserção do enfoque CTSA no cursos de formação inicial de professores de química na região semi-árida do sertão nordestino do Brasil.

\section{Marco Teórico}

\footnotetext{
1 Instituto Federal de Educação, Ciência e Tecnologia do Rio Grande do Norte (IFRN). albino.nunes@ifrn.edu.br

2 Universidade Federal do Rio Grande do Norte (UFRN). josivaniamd@yahoo.com.br

3 Universidade do Estado do Rio Grande do Norte(UERN). souzaluizdi@gmail.com
} 
Revista Tecné, Episteme y Didaxis: TED. Año 2014, Número Extraordinario. ISSN Impreso: 0121-3814, ISSN web: 2323-0126

Memorias, Sexto Congreso Internacional sobre Formación de Profesores de Ciencias. 08 al 10 de octubre de 2014, Bogotá

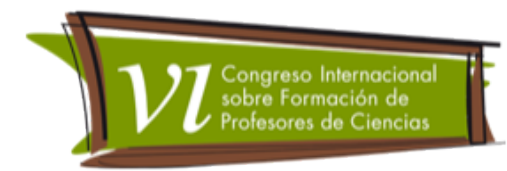

O movimento Ciência-Tecnologia-Sociedade (CTS) surgiu nos Estados Unidos da América, na educação universitária, entre as décadas de 60 e 70 . Esse momento histórico ficou marcado pela efervescência de diversos estudos em áreas limites entre o trinômio CTS, como a existência de duas culturas discutida por C.P. Snow e os limites do crescimento denunciados por Dennis Meadows. Enquanto um campo de estudo a sigla CTS designa tendências diferentes no estudo social da ciência e da tecnologia, surgidas como resposta à relação desequilibrada que a sociedade mantinha com a ciência e a tecnologia (Membiela, 2001 e Cerezo, 1998).

Alguns autores como Sutil (2008) situam no pós Segunda Guerra e na descrença gerada com os efeitos danosos da ciência e tecnologia, o surgimento do campo de estudo designado como CTS. O que passou a ser questionado naquele momento histórico foi a pretensa relação linear existente entre Ciência e Tecnologia (CT) e a sociedade. Segundo essa perspectiva o desenvolvimento do binômio CT significaria invariavelmente um avanço do bem-estar social.

Ainda sobre a história do CTS, García, López Cerezo \& Luján (1996) destacam dentro do movimento tradições de pesquisa que foram designadas pela mesma sigla: STS, do inglês 1) Science and Tecnology Studies (tradição Européia) e 2) Science, Tecnology and Society, (tradição americana).

- No tocante à consolidação do movimento Cerezo (1998) sumariza três grandes direções tomadas pelos estudos CTS desde sua origem:

- No campo de investigação, os estudos CTS tem proporcionado uma reflexão contextualizada para a construção do conhecimento científico enquanto um processo social;

- No campo político tem defendido o controle social da ciência e da tecnologia e a criação de mecanismos democráticos desse controle.

- Na educação, tem impulsionado o aparecimento de inúmeras propostas e materiais didáticos que visem discutir a ciência e a tecnologia como processos sociais.

Mediante a discussão do movimento CTS, mais recentemente tem-se defendido a sigla CTSA, como forma de dar maior destaque às questões ambientais dentro da discussão sobre CT. Segundo Tomazello (2009) a letra "A" foi incorporada à sigla tradicional CTS, quando da transposição do campo de estudo para o ensino de ciências. 
Revista Tecné, Episteme y Didaxis: TED. Año 2014, Número Extraordinario. ISSN Impreso: 0121-3814, ISSN web: 2323-0126

Memorias, Sexto Congreso Internacional sobre Formación de Profesores de Ciencias. 08 al 10 de octubre de 2014, Bogotá

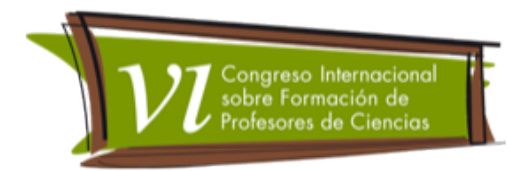

A partir dessa perspectiva teórica é que elaboramos uma unidade didática para trabalhar as relações CTSA para a licenciatura em química. A referida unidade foi projetada a partir da realidade local da cidade de Mossoró que faz parte da bacia hidrográfica do Rio Apodi-Mossoró e conta com o curso de licenciatura em química.

\section{Metodologia}

A elaboração do material didático foi realizada com base em três principais eixos:

1. Revisão bibliográfica sobre as concepções, atitudes, crenças e visões de professores em formação e professores em exercício;

2. Levantamento das atitudes e crenças dos licenciandos pesquisados sobre as relações CTSA;

3. A necessidade de dialogar com livro "Química e Sociedade", tendo em vista que este apresenta um enfoque CTS para o ensino-aprendizagem em química e que é um dos livros aprovados no último Programa Nacional do livro didático do Ensino Médio (PNLEM).

Para cumprir tais objetivos foram elaborados 3 módulos de ensino contendo respectivamente elementos de epistemologia da ciência, discussão das relações CTSA e uma unidade didática para o contexto local. A estrutura geral do material pode observada abaixo:

Módulo 1: Questionando a hegemonia do conhecimento tecno-científico;

Módulo 2: As relações entre a ciência, a tecnologia, o ambiente e a sociedade movimento CTSA;

Módulo 3: Proposta temática para a educação química em uma perspectiva CTSA: O rio mossoró.

Como já discutido acima, os estudantes, licenciados e professores possuem crenças e atitudes que segundo Manassero Mas e Vazquez Alonso (2001) seriam denominadas ingênuas ou inadequadas das quais pode-se citar:

- O mito da verdade absoluta;

- O realismo ingênuo;

- A negação de influência de fatores sociais sobre a ciência; 
Revista Tecné, Episteme y Didaxis: TED. Año 2014, Número Extraordinario. ISSN Impreso: 0121-3814, ISSN web: 2323-0126

Memorias, Sexto Congreso Internacional sobre Formación de Profesores de Ciencias. 08 al 10 de octubre de 2014, Bogotá

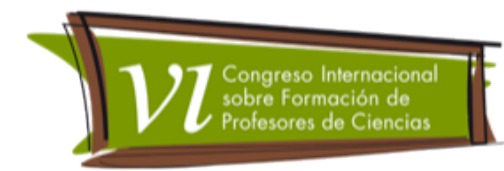

Retomando-se os dados analisados no terceiro capítulo nota-se claramente que os licenciandos pesquisados apresentam em grande medida estas crenças.

Sendo assim, a proposta do primeiro módulo de ensino volta-se a discutir elementos de epistemologia da ciência que diretamente se relacionam com o enfoque CTSA.

Desta forma, o primeiro módulo busca fazer uma brevíssima síntese de idéias contidas nas epistemologias positivistas, poperiana, kunhiana,e de Paul Feyrebend, dando destaque às críticas feitas ao modelo positivista de entendimento da ciência.

A construção do segundo módulo foi motivada pela intencionalidade de discutir cada um dos componentes do sistema CTSA. Tendo em vista a percepção de que algumas crenças apresentadas pelos estudantes pesquisados: a) A perspectiva salvacionista; b) O não entendimento da relação entre Ciência e Tecnologia ; c) A aceitação do modelo tecnocrático de decisão.

O terceiro módulo foi elaborado com base na realidade local da degradação do Rio Apodi-Mossoró. Este rio passa por três importantes cidades do interior do estado do Rio Grande do Norte(Brasil) que atualmente contam com cursos de licenciatura em química: Mossoró, Apodi, e Pau dos Ferros. Na primeira destas cidades o rio sofre uma tricotomização e divide a cidade.

Com o mesmo intuito de avaliar essa unidade proposta foram realizadas no dia 09 e 10 de fevereiro de 2010 as oficinas intituladas "Relações CTSA no ensino de química". Estas contaram com 12 horas/aula distribuídas no turno vespertino do dia 09, e matutino e vespertino do dia 10, com descrito na tabela 1. Participaram no total da oficina 32 licenciandos de todos os períodos do curso $\left(2^{\circ}, 4^{\circ}, 6^{\circ}\right.$ e $\left.8^{\circ}\right)$.

Tabela 1: Estrutura da oficina na UERN

\begin{tabular}{|l|l|l|l|}
\hline Dia & Turno & Tempo & Atividades \\
\hline 09 & $\mathrm{~V}$ & $4 \mathrm{~h} / \mathrm{a}$ & $\begin{array}{l}\text { Apresentação } \\
\text { Início da Atividade Experimental } \\
\text { Discussão sobre questões epistemológicas }\end{array}$ \\
\hline 10 & $\mathrm{M}$ & $4 \mathrm{~h} / \mathrm{a}$ & $\begin{array}{l}\text { Apresentação da estrutura do Caso Simulado CTSA } \\
\text { Escolha do tema e formação dos grupos par o caso Simulado CTSA. } \\
\text { Debate sobre as relações CTSA } \\
\text { Apresentação de vídeos ilustrativos }\end{array}$ \\
\hline 10 & $V$ & $4 \mathrm{~h} / \mathrm{a}$ & $\begin{array}{l}\text { Discussão sobre a atividade experimental } \\
\text { Realização do Caso Simulado } \\
\text { Avaliação. }\end{array}$ \\
\hline
\end{tabular}


Revista Tecné, Episteme y Didaxis: TED. Año 2014, Número Extraordinario. ISSN Impreso: 0121-3814, ISSN web: 2323-0126

Memorias, Sexto Congreso Internacional sobre Formación de Profesores de Ciencias. 08 al 10 de octubre de 2014, Bogotá

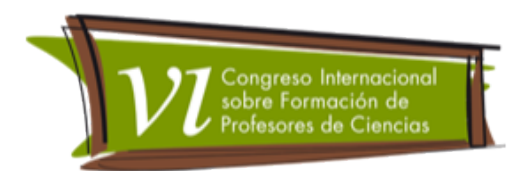

\section{Resultados}

Terminado o caso simulado, passou-se a entrevista grupal na qual os estudantes foram questionados inicialmente sobre o caso simulado e em seguida, sobre a própria oficina.

Todos os participantes afirmam ter gostado da atividade (Caso Simulado) e que esta poderia ser usada no ensino de química, e que mesmo nessa abordagem os conteúdos químicos poderiam ser trabalhados, sem prejuízos.

Segundo um dos participantes uma limitação para se usar o debate sobre o rio Mossoró em uma sala de aula de ensino médio seria a linguagem como podemos notar em sua fala.

"... A dificuldade seria a linguagem para aplicar no ensino médio... o que estou dizendo é pegar os conceitos e falar numa linguagem mais acessível ao pessoal..." (Estudante B)

Foi discutido ainda o papel que cada grupo representava dentro da perspectiva e que o grupo de cientistas tinha especial importância dado ser o grupo que abordaria dentro do debate os conceitos químicos. Por sua vez o grupo de jurados representava um papel ainda mais importante por ter a responsabilidade de buscar soluções possíveis para o problema com base nos argumentos apresentados por todos os grupos. O que poder ser ilustrado da fala de um dos participantes:

"o diferencial é que os jurados não vão dizer quem tá certo, quem tá errado. Aí fica mais interessante..."(Estudante C)

Quando questionados sobre a oficina e sobre os pontos positivos, estes levantaram dois pontos: o experimento e os recursos utilizados (charges, vídeos, músicas). Uma estudante retomou ao experimento para diferenciá-los dos demais que são feitos em sala.

"Nesse experimento nós podemos mostrar uma coisa real, não é só aqueles experimentos que costumamos fazer." (Estudante A)

Os estudantes também foram perguntados se a linguagem usada na oficina poderia ter sido uma dificuldade, ao que um dos participantes respondeu: 
Revista Tecné, Episteme y Didaxis: TED. Año 2014, Número Extraordinario. ISSN Impreso: 0121-3814, ISSN web: 2323-0126

Memorias, Sexto Congreso Internacional sobre Formación de Profesores de Ciencias. 08 al 10 de octubre de 2014, Bogotá

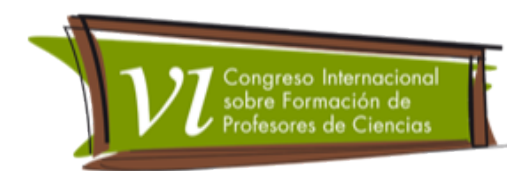

"Não acho que a linguagem em si, mas é porque a gente não estava acostumado com alguns autores, alguns conceitos eu não conhecia, por exemplo, a "ciência anarquista" [ao se referir ao anarquismo epistemológico de Paul Feyreband]. (Estudante C)

Foram pontos negativos levantados nesse momento, por outro licenciando que as discussões epistemológicas foram "monótonas" (Estudante E). Ao que o Estudante B, discordou afirmando que a questão estava no interesse de cada um. Alguns gostavam mais da parte experimental ele, por exemplo, tinha gostado mais do debate e da discussão epistemológica.

Um ponto também levantado foi a grande evasão do curso. Dos trinta e dois participantes que iniciaram o curso apenas 15 estiveram presentes no último momento. Contudo, foi observado que parte dos estudantes que faltaram à atividade tiveram aula no mesmo horário.

\section{Conclusão}

As oficinas demonstram, no entanto, algumas fragilidades na unidade didática e em seu material de suporte, que requerem revisões posteriores de linguagem para melhor adequação ao objetivo. Mas também demonstraram que tanto o experimento proposto, quanto o caso simulado são atividades que podem colaborar para uma alfabetização científica e tecnológica (ACT) dos licenciandos dentro da perspectiva do entendimento do conhecimento da tecnociência e suas relações com a sociedade e o ambiente. O discurso dos licenciandos reforça, ainda, a idéia de que objetivo de elaborar um material de apoio contextualizado e que dialogasse com a realidade local foi alcançado.

Por outro lado, notaram-se também as necessidades que indicam a continuidade da pesquisa em dois pontos:

1. Elaboração de um quarto módulo de ensino que discutisse com profundidade o letramento científico e tecnológico juntamente com as perspectivas do movimento CTSA na educação brasileira e

2. O aprofundamento da proposta de inserção das relações CTSA no currículo da licenciatura a partir da inserção de elementos de discussão das relações entre ciência-tecnologia-sociedade e ambiente dentro de cada disciplina específica de química, não apenas na instrumentação para o ensino. 
Revista Tecné, Episteme y Didaxis: TED. Año 2014, Número Extraordinario. ISSN Impreso: 0121-3814, ISSN web: 2323-0126

Memorias, Sexto Congreso Internacional sobre Formación de Profesores de Ciencias. 08 al 10 de octubre de 2014, Bogotá

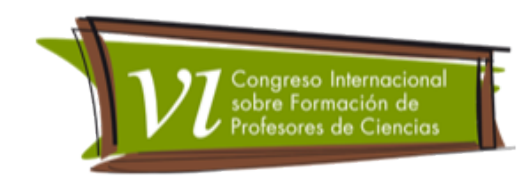

Ambos os objetivos atualmente estão sendo pensados no projeto de doutorado do primeiro autor, que constitui-se na continuidade do trabalho ora relatado.

\section{Referencias Bibliográficas}

Cerezo, J. A. L. (1998). Ciencia, Tecnología y Sociedad: el estado de la cuestión en Europa y Estados Unidos, Revista Iberoamericana de Educación, 18< http://www.rieoei.org/oeivirt/rie18a02.htm>.

García, M. I. G., López Cerezo, J. A. \& Lujan López, J. L. (1996). Ciencia, tecnología y sociedad: una introducción al estudio social de la ciencia y la tecnología. Madri: Tecnos.

Manassero, M. A. \& Vázquez, A. (2001). Atitudes e creencias de los estudiantes relacionadas com CTS. In Membiela, P.(org.) Enseñanza de las ciencias desde la perspectiva Ciencia-Tecnología-Sociedad: Formación científica para laciudadanía. Madrid: Narcea.

Membiela, P. (2001). Uma revisión del movimiento CTS em La enseñanza de las Ciencias. In (org.). Enseñanza de las Ciências desde la perspectiva CiênciaTecnología-Sociedad: Formación científica para la ciudadanía. Madrid: Nancea.

Sutil, N. (2008). CTS E CTSA em periódicos nacionais em Ensino De Ciências/Física (20002007): Aspectos Epistemológicos e Sociológicos. In Anais do XI Encontro de Pesquisa em Ensino de Física, Curitiba.

Tomazello, M. G. C. (2009). O Movimento Ciência, Tecnologia - Sociedade - Ambiente na Educação em Ciências. In Anais do I Seminário Internacional de Ciência, Tecnologia e Ambiente, Cascavel. 